\title{
The effects of physical environment, time in captivity, and defensive distance on tonic immobility, freezing, and flight behaviors in Anolis carolinensis
}

\author{
CHARLES W. HENNIG \\ Tulane University, New Orleans, Louisiana 70118
}

\begin{abstract}
The effects of physical environment, time in captivity, and distance between potential predator and prey on defensive behaviors were examined in Anolis carolinensis. When the experimenter was nearby, duration of immobility was significantly longer in the open than in areas with nearby foliage. However, this relationship between duration of immobility and the testing environment in the anole was reversed by Day 9 in captivity. Flight latency of anoles after termination of immobility was significantly shorter in anoles housed in terraria containing foliage, while greater incidence of freezing was shown by anoles housed in empty terraria. These results suggest that although the physical environment has strong effects on defense behaviors, the different defensive reactions are influenced in different ways.
\end{abstract}

Ethologists have long maintained that environmental factors are important in understanding the behavior of animals, especially behaviors such as habitat selection, feeding, predator defense, and social organization (e.g., Edmunds, 1974; Jarman, 1974; Eibl-Eibesfeldt, 1975). The involvement of environmental factors is particularly important in understanding an organism's behavior in the laboratory, rather than in its natural surroundings. A number of naturalistic studies with several different anoline species have shown that lizards select an appropriate habitat when given a choice between several different habitats (Kiester, Gorman, \& Arroyo, 1975; Talbot, 1977). Heatwole (1968) has also noted that the availability of nearby camouflage can increase the defensive distance of certain anoles.

Tonic immobility (TI), a behavior observed in a wide variety of species, has been thought of by a number of authors to represent a predator defense (for a review, see Gallup, 1974). A naturalistic study by Sargeant and Eberhardt (1975) demonstrated the survival value of tonic immobility in wild ducks that went immobile when seized and were subsequently hidden or buried by foxes, since 29 out of 50 animals later arose when the fox had left and thus survived their initial capture. Duration of immobility is increased by the presence of a simulated predator in domestic chickens (Gallup, Nash, Donegan, \& McClure, 1971; Gallup, Nash, \& Ellison, 1971;

Portions of this paper were presented at the meeting of the Midwestern Animal Behavior Society in West Lafayette, Indiana, in March 1978. Requests for reprints should be sent to Charles W. Hennig, now at the Department of Psychology, University of Oklahoma, Norman, Oklahoma 73019.
Gallup, Cummings, \& Nash, 1972) and anoles (Edson \& Gallup, 1972; Gallup, 1973; Hennig, 1977), by shorter distances between potential predator and prey in the same two species (Ginsburg, 1975; Hennig, Dunlap, \& Gallup, 1976), and the environmental opportunity for escape in the blue crab (O'Brien \& Dunlap, 1975), crayfish (Garrison, 1976), and the anole (Hennig et al., 1976).

Previous research has also suggested that these factors may interact. Hennig et al. (1976) showed that the presence of foliage during testing with a nearby potential predator decreased the duration of TI in anoles, while testing in an open area increased the duration of immobility. Hennig and Dunlap (1978) found that foliage in the housing environment similarly decreased the duration of TI in anoles on their 3rd day in captivity, but not on Days 1 or 7 . The effects and possible interactions between housing environment, testing environment, predator-prey defensive distance, and time in captivity are examined in the present study using the anole lizard, Anolis carolinensis, in order to elucidate how the previous individual findings fit together in a complete picture of the defensive process. In addition to duration of immobility, flight latency was also recorded in order to determine if environmental factors affect these defensive behaviors in a similar manner.

\section{METHOD}

\section{Subjects}

Two hundred sixty-four anoles (Anolis carolinensis) of approximately equal numbers of both sexes and undetermined age, ranging in length from 4 to $7 \mathrm{~cm}$ (snout-vent) were collected locally at night, with the aid of head-mounted flashlights, and housed in 12 glass terraria in groups of 22 anoles each. Six 
terraria contained various types of foliage and small sticks, while the other six were empty. The terraria were sprinkled daily with water, and mealworms were offered on alternate days, starting with the 2 nd day of captivity. The room temperature was maintained at approximately $25^{\circ} \mathrm{C}$ and the photoperiod in effect throughout the study was $14 \mathrm{~h}$ of artificial light ( 6 a.m. -8 p.m.).

\section{Apparatus \\ The 12 glass housing terraria were $52 \times 27 \times 30 \mathrm{~cm}$. Anoles were individually transported to the testing area in small glass fish bowls $(13 \times 13 \times 9 \mathrm{~cm})$. The testing area was an ordinary brown table with a circle of $15 \mathrm{~cm}$ radius drawn on it near the edge. The center of this circle was the induction point for all testing. In one test condition the table was empty, while in the i)ther condition various foliage, including shrubs, sticks, and aspidistra leaves, were positioned on the perimeter of the circle at approximately $15 \mathrm{~cm}$ radius from the central induction point, forming a semicircular area $10 \mathrm{~cm}$ deep and $20 \mathrm{~cm}$ high.}

\section{Design}

The first 132 anoles were captured and tested in a 2 by 2 by 3 factorial design with two housing conditions (empty terraria or those containing foliage), two testing conditions (empty table or semicircle of foliage), and three different days of testing (Day 1 , 3 , or 9 in captivity), with the experimenter seated $30 \mathrm{~cm}$ away. Following that study, another 132 anoles were captured and tested under all of the same conditions, except that the experimenter was seated $90 \mathrm{~cm}$ away from the subject during testing. Each day, the subjects were tested in randomly ordered replications containing a subject from each of the four groups so that possible circadian rhythm effects would be evenly distributed across groups.

\section{Procedure}

The general testing procedure for this experiment was as follows. The experimenter randomly chose an anole from the appropriate housing condition on the day it was scheduled to be tested. The subject was carried into the testing room in a small glass fish bowl. The appropriate test condition was arranged (either an empty table or a table with a semicircle of foliage) and then the subject was seized again. It was inverted on its back (with the head-tail axis oriented left to right) by the experimenter at the central induction point, and held down with moderate pressure by one fingertip on the base of its lower jaw and another on the tip of its tail. After $20 \mathrm{sec}$, the subject was gently released. The experimenter started to time the duration of immobility with a stopwatch from the removal of restraint until a spontaneous righting response occurred. If immobility did not last at least $10 \mathrm{sec}$ on the first attempt, manual restraint was immediately reapplied as many times as necessary, up to a maximum of 10 attempts, to produce an immobility response of at least $10 \mathrm{sec}$ duration. All subjects showed TI within these limits. Once immobility was induced, the experimenter sat down in a chair located so that the distance from the subject to the experimenter's eyes was either 30 or $90 \mathrm{~cm}$, depending upon the experiment. The experimenter observed the subject with an indirect gaze, making sure not to stare directly at the anole for prolonged periods or to make any unnecessary noises or movements, and recorded the duration of immobility for each subject. When the subject terminated the immobility episode, flight latency was recorded. Flight latency was defined as the time between the righting of the subject and when the rear legs of the anole crossed a circular line $15 \mathrm{~cm}$ radius from the point of induction. A maximum of $30 \mathrm{sec}$ was allowed for flight latency.

\section{RESULTS}

Multivariate analyses of variance (MANOVA) were performed on the data for the two dependent variables, duration of $\mathrm{TI}$ and flight latency, at each subject-experimenter distance. A three-way MANOVA revealed a significant multivariate effect of housing environment [Rao's approximate $\mathrm{F}(2,119)=3.23$, $\mathrm{p}=.043 \mathrm{i}]$ and a significant interaction between day of captivity and testing environment [Rao's approximate $F(4,238)=3.23, p=.0132$ ] at the $30-\mathrm{cm}$ distance. A three-way MANOVA on the data for the $90-\mathrm{cm}$ distance revealed a significant multivariate effect of housing [Rao's approximate $F(2,119)=$ $5.23, \mathrm{p}=.0067]$ and the effect of day of captivity approached accepted levels of significance [Rao's approximate $F(4,238)=2.28, p=.0614]$. Significant multivariate effects were followed by univariate analyses of variance (ANOVA) in order to help interpret the findings.

The mean durations of immobility for each cell represented in the two factorial designs, 30 - and $90-\mathrm{cm}$ subject-experimenter defensive distances, are shown in Figure 1. As seen in the upper part of the figure, where the distance between subject and experimenter
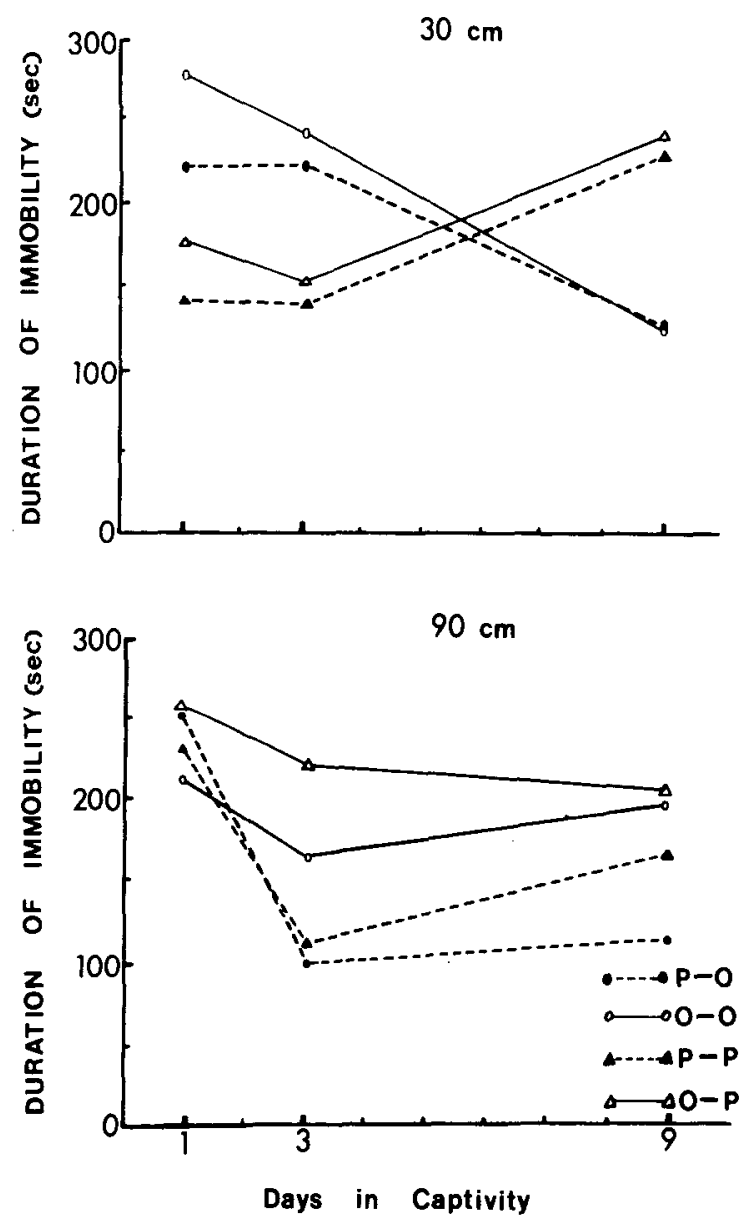

Figure 1. Mean durations of tonic immobility on Day 1,3 or 9 in captivity in anoles housed and tested in different environments $(0-O=$ housed in open and tested in open, $\mathrm{O}-\mathrm{P}=$ housed in open and tested near plants, P-P = housed with plants and tested near plants, P-O = housed with plants and tested in open), with subject-experimenter distances of $30 \mathrm{~cm}$ (upper figure) or $90 \mathrm{~cm}$ (lower figure). 
was $30 \mathrm{~cm}$, the duration of $\mathrm{TI}$ during testing in an open area on Days 1 and 3 was longer than that of subjects tested in the presence of nearby foliage, regardless of the housing environment; however, this relationship was reversed for the anoles tested on Day 9. A three-way factorial ANOVA performed on these data, with housing environment, testing environment, and day of testing as the independent variables, supported these findings. Only the interaction between the testing environment and day in captivity was significant $[\mathrm{F}(2,120)=6.66, \mathrm{p}=.0018]$. Analyses of the simple effects on each of the various days for testing showed that the duration of TI was significantly longer in the open testing situation than with nearby foliage on Days 1 and 3 in captivity $[F(1,120)=4.29, p=.0405$, and $F(1,120)=3.93$, $\mathrm{p}=.0497$, respectively], while the duration of TI in the open testing situation was significantly shorter than with the foliage nearby on Day $9[F(1,120)=$ $6.00, \mathrm{p}=.0157]$.

For anoles tested at a $90-\mathrm{cm}$ distance between subject and experimenter, the housing environment rather than the testing environment appeared to be the most potent variable. The mean durations of TI for each cell in this experiment are shown in the lower part of Figure 1. As can be seen, there appears to be little difference due to conditions on Day 1, while a trend for longer durations of TI for anoles housed in empty terraria appears on Day 3 and to a lesser extent again on Day 9. A three-way ANOVA showed, however, that only the main effect of day of testing was significant $[F(2,120)=3.59, p=.0306]$. The main effect of housing environment did not reach accepted levels of significance $[F(1,120)=2.69, p=$ .1036]. Analyses of the simple effects on each day of testing revealed that only the housing environment on Day 3 approached significance $[F(1,120)=3.20$, $p=.0762]$.

The mean flight latencies for anoles tested at the 30-cm subject-experimenter distance are shown in the upper part of Figure 2. As can be seen, anoles housed in terraria with foliage were more likely to flee soon after termination of TI, while those anoles in empty terraria were likely to freeze for more extended periods. This was supported by a significant main effect of housing environment $[F(1,120)=6.48, p=.0122]$. The lower part of Figure 2 shows a similar trend for flight latencies tested at $90-\mathrm{cm}$ subject-experimenter distances. This was supported by a significant main effect by housing environment $[F(1,120)=9.98$, $\mathrm{p}=.0020$ ], with longer flight latencies shown by anoles housed in empty terraria. All other factors failed to reach significance.

\section{DISCUSSION}

Many environmental variables are known to affect the behavior of animals. One of the most evident,
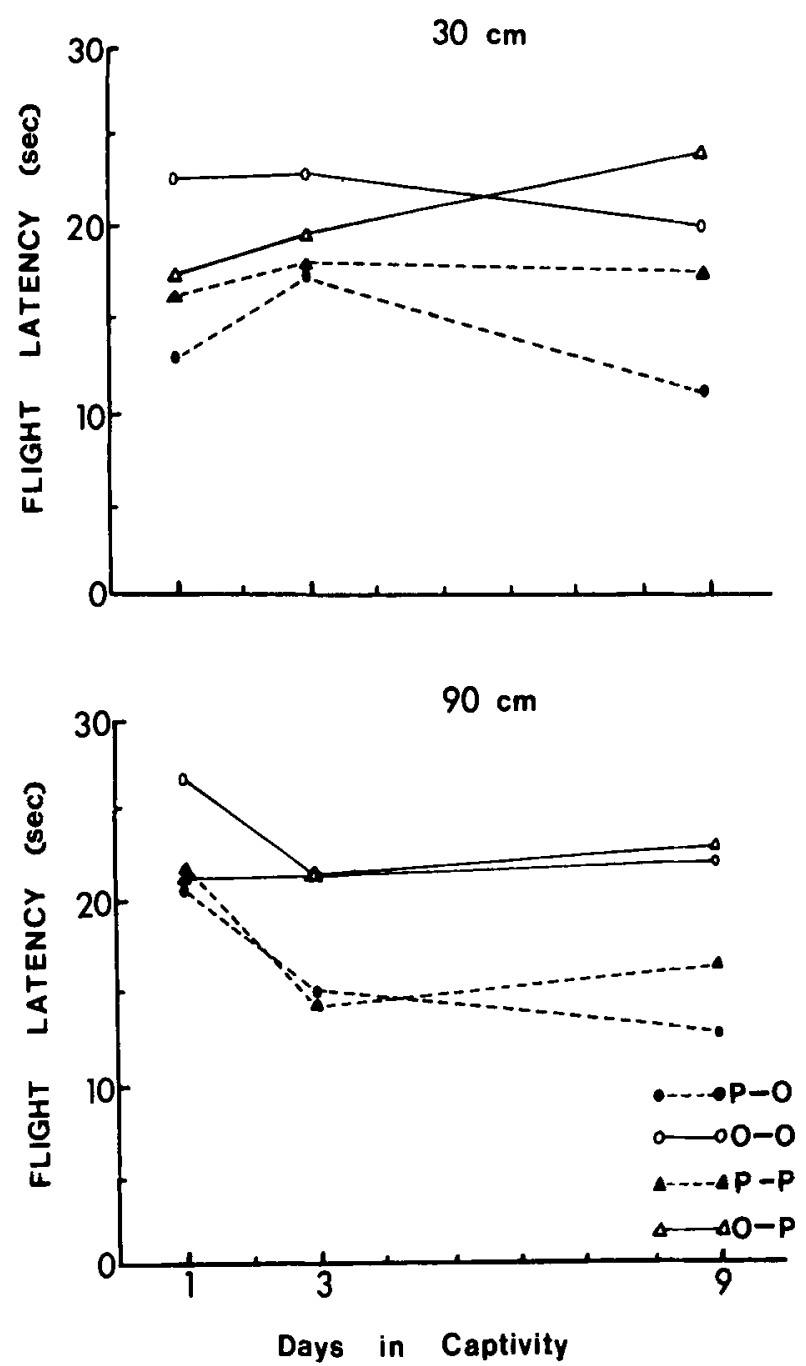

Figure 2. Mean flight latencies after termination of tonic immobility on Day 1, 3, or 9 in captivity in anoles housed and tested in different environments $(0-0=$ housed in open and tested in open, O-P $=$ housed in open and tested near plants, $\mathbf{P}-\mathbf{P}=$ housed with plants and tested near plants, P-O = housed with plants and tested in open) with subject-experimenter distances of $30 \mathrm{~cm}$ (upper figure) or $90 \mathrm{~cm}$ (lower figure).

yet least understood, is the effect of capture and confinement. Ultimately, captivity makes the survival of an animal less dependent on antipredator defenses, food and water availability, climate, and shelter; but the captive animal is now subject to atypical stress, including an invasion of personal space, reduced exercise, deprivation of natural releasing stimuli, and a change in diet (Hediger, 1964). Descendents of domesticated strains often appear less responsive to various stimuli than the descendents of wild strains (Barnett, 1958; Price, 1970, 1973), and domestic animals are usually considered less emotional, timid, and savage than their wild progenitors (Galef, 1970). Many authors suggest that behavioral differences are due to genetic changes caused by artificial selection prior to and during captivity (Mayr, 1974). An opposing explanation is that individual experience affects emotional behavior, producing rapid changes in 
some behaviors, especially defense reactions. Price and Huck (1976) found differences in open-field behavior in wild and domestic Norway rats, while Boice (1977) and Flannelly and Lore (1977) found no differences between wild and domestic rats if they were housed in burrows. The latter studies support Daly's (1973) hypothesis that rodent behavior should be more normal in burrows than in open areas. Clark and Galef (1977) found similar results with gerbils, while other studies with mice and rats found a somewhat analogous relationship between activity and a small place to hide (Manosevitz \& Pryor, 1975; Syme \& Syme, 1976). Together, these results suggest a strong influence of physical environment on behavior, and that quality rather than quantity may be the crucial factor.

The present study showed that at $30-\mathrm{cm}$ subjectexperimenter defensive distances, anoles were sensitive to the immediate testing environment, with significantly longer durations of TI in open areas than near foliage. This result replicates the findings of Hennig et al. (1976) with anoles, and similar results by O'Brien and Dunlap (1975) with blue crabs on sand and solid surfaces, and by Garrison (1976) with crayfish on sand or mud. There was, however, a reversal of the anole's response to the environment by Day 9 in captivity. At a $90-\mathrm{cm}$ subject-experimenter distance, anoles were not sensitive to the testing environment but did show effects of the housing environment on Day 3 in captivity, but not on Day 1 or Day 9, which supports the findings of Hennig and Dunlap (1978) that housing environment affects the duration of TI by the third day in captivity. This effect occurs at greater subject-experimenter distances where the tester represents less of an immediate threat. Thus, the immediate testing environment is more important when a potential predator (the experimenter) was nearby, and housing is more important at greater distances and after the first few days of adaptation to the new conditions. These results further support the findings of Ginsburg (1975) with chickens and Hennig et al. (1976) with anoles concerning the importance of distance between predator and prey on tonic immobility.

The other dependent variable, flight latency, was only sensitive to the type of housing environment during captivity. Flight was more likely than freezing in anoles that were housed in terraria containing foliage for concealment. There seemed to be no strong changes in flight latency over days in captivity or with different defensive distances. This finding seems to be contradictory to Ratner's (1967) hypothesis that freezing and flight should be distance dependent and suggests that immobility may be the more distance-dependent variable. Tonic immobility seems to be responsive to both changes in testing environment and time in captivity, while flight laten- cy was only sensitive to changes in housing environment.

The present results suggest that the lizard may be a better choice than the more commonly used rodents in studies of the effect of environment on behavior. Many experiments have failed to find robust effects of environment on adult mammals, while poikilothermic animals usually react quickly to small changes in the environment, at least within their normal operating range. Crews (1975) has shown this to be true for the effect of humidity and light on sexual behavior in anoles. Moreover, Heatwole (1968) has noted that the availability of nearby camouflage affected the defensive distances in certain anoline species, which parallels the findings of the present study.

One of the strongest effects in the present study, yet the most difficult to explain, is the reversal of the anole's response to the test environment for duration of TI on Day 9 in captivity at the $30-\mathrm{cm}$ defensive distance. Boice and Williams (1971) found a decrease in susceptibility to TI in frogs over a period of months in captivity. The reversal in the duration of TI on Day 9 is, however, harder to explain. There seems to be some kind of interaction between test environment and time in captivity. Richter (1950) maintained that the adrenal glands of captive wild rats are enlarged during the first 7 days in captivity, but then return to normal. If a similar result occurred in anoles, perhaps a return to normal hormone levels by Day 9 caused the reversal in immobility reactions to the testing environment. Although this finding defies a concrete explanation for the moment, it does make clear that complex interactions of environmental factors can occur, especially with an organism such as the anole that is intimately related to its surroundings.

\section{REFERENCES}

Barnett, S. A. Experiments on "neophobia" in wild and laboratory rats. British Journal of Psychology, 1958, 49. 195-201. Borce, R. Burrows of wild and albino rats: Effects of domestication, outdoor raising, age, experience, and maternal state. Journal of Comparative and Physiological Psychology, 1977. 91. 649-661.

Boice, R., \& Williams, R. C. Delay in onset of tonic immobility in Rana pipiens. Copeia, 1971, 4, 747.748.

Clark, M. M., \& Galef, B. G., JR. The role of the physical rearing environment in the domestication of the Mongolian gerbil (Meriones unguiculatus). Animal Behaviour, 1977, 25. 298-316.

Crews, D. Psychobiology of reptilian reproduction. Science, 1975. 189. 1059-1065.

DALY, M. Early stimulation of rodents: A critical review of present interpretations. British Journal of Psychology, 1973. 64. 435-460.

EDMunds, M. Defense in animals. A survey of anti-predator defenses. Essex, England: Longman, 1974.

Edson. P. H., \& Gallup, G. G.. JR. Tonic immobility as 
a fear response in lizards (Anolis carolinensis). Psychonomic Science, 1972, 26, 27-28.

EIBL-EIBESFELDT, I. Ethology. The biology of behavior (2nd ed.). New York: Holt, Rinehart \& Winston, 1975.

Flannelly, K.. \& Lore, R. Observations of the subterranean activity of domesticated and wild rats (Rattus norvegicus): A descriptive study. Psychological Record, 1977. 27, 315-329.

GALEF, B. G.. JR. Aggression and timidity: Responses to novelty in feral Norway rats. Journal of Comparative and Physiological Psychology, 1970, 70, 370-381.

Gallup. G. G.. JR. Simulated predation and tonic immobility in Anolis carolinensis. Copeia, 1973, 3, 623-624.

Gallup. G. G., JR. Animal hypnosis: Factual status of a tictional concept. Psychological Bulletin, 1974, 81, 836-853.

Gallup, G. G.. JR., Cummings, W. H., \& Nash, R. F. The experimenter as an independent variable in studies of animal hypnosis in chickens (Gallus gallus). Animal Behaviour. 1972, 20, 166-169.

Gallup, G. G., JR., Nash, R. F., Donegan, N. H., \& MCCluRE, M. K. The immobility response: A predatorinduced reaction in chickens. Psychological Record, 1971, 21. 513-519.

Gallup, G. G., JR., Nash, R. F., \& Ellison, A. L., JR. Tonic immobility as a reaction to predation: Artificial eyes as a fear stimulus for chickens. Psychonomic Science, 1971, 23, 79-80.

Garrison. S. C. Tonic immobility in the crayfish (Procambarus clarkii): Effects of environment. simulated predation, and habituation. Unpublished doctoral dissertation, Tulane University, 1976.

GinsBurg. H. J. Defensive distance and immobility in young precocial birds (Gallus gallus). Developmental Psychobiology, 1975, 8. 281-285.

Heatwole, H. Relationship of escape behavior and camouflage in anoline lizards. Copeia, 1968, 1, 109-113.

Hediger, H. Wild animals in captivity. New York: Dover, 1964.

HENNIG, C. W. Effects of simulated predation on tonic immobility in Anolis carolinensis: The role of eye contact. Bulletin of the Psychonomic Society, 1977, 9, 239-242.

Hennig. C. W.. \& DunlaP, W. P. Tonic immobility in Anolis carolinensis: Effects of time and conditions of captivity. Behavioral Biologv, 1978, 23, 75-86.

Hennig, C. W., Dunlap, W. P., \& Gallup, G. G., JR. The effect of distance between predator and prey and the opportunity to escape on tonic immobility in Anolis carolinensis. Psychological Record, 1976, 26, 313-320.

JARMAN, P. J. The social organization of antelope in relation to their ecology. Behaviour, 1974, 48. 215-267.

Kiester, A. R.. Gorman, G. C., \& Arroyo, D. C. Habitat selection behavior of three species of Anolis lizards. Ecology, 1975, 56, 220-225.

MAYR, E. Behavior programs and evolutionary strategies. American Scientist, 1974, 62, 650-659.

Manosevitz, M., \& PRyor, J. B. Cage size as a factor in environmental enrichment. Joumal of Comparative and Physiological Psychology, 1975, 89, 648-654.

O'Brien, T. J.. \& DunlaP. W. P. Tonic immobility in the blue crab (Callinectes sapidus, Rathbun): Its relation to threat of predation. Journal of Comparative and Physiological Psychology. 1975, 89, 86-94.

Price, E. O. Differential reactivity of wild and semi-domestic deermice (Peromyscus maniculatus). Animal Behaviour, 1970. 18, 747.752.

PRICE, E. O. Some behavioral differences between wild and domestic Norway rats: Unawing and platform jumping. Animal Learning \& Behavior, 1973, 1, 312-316.

Price, E. O.. \& Huck, U. W. Open-field behavior of wild and domestic Norway rats. Animal Learning \& Behavior, 1976, 4, 125-130.

RATNer, S. C. Comparative aspects of hypnosis. In J. E. Gordon (Ed.), Handbook of clinical and experimental hypnosis. New York: Macmillan, 1967.

Richter, C. P. Domestication of the Norway rat and its implications for the problems of stress. Proceedings of the Association for Research in Nervous and Mental Diseases. $1950,29,19-47$

Sargeant, A. B., \& Eberhardt, L. E. Death feigning by ducks in response to predation by red foxed (Vulpes fulva). American Midland Naturalist, 1975, 94, 108-119.

Syme, L. A., \& Syme, G. J. Spatial interaction between cage and test environments: Position preferences of young isolated and pair-housed rats. Animal Learning \& Behavior, 1976. 4. $396-400$

TALBOT, J. J. Habitat selection in two tropical anoline lizards. Herpetologica, 1977, 33, 114-123.

(Received for publication March 24, 1978; revision accepted June 28,1978 .) 